This is an electronic reprint of the original article. This reprint may differ from the original in pagination and typographic detail.

Author(s): Kokko, Sami; Villberg, Jari; Kannas, Lasse

Title: Health Promotion in Sport Coaching: Coaches and Young Male Athletes' Evaluations on the Health Promotion Activity of Coaches

Year: $\quad 2015$

Version:

Please cite the original version:

Kokko, S., Villberg, J., \& Kannas, L. (2015). Health Promotion in Sport Coaching: Coaches and Young Male Athletes' Evaluations on the Health Promotion Activity of Coaches. International journal of Sports Science and Coaching, 10(2-3), 339-352. https://doi.org/10.1260/1747-9541.10.2-3.339

All material supplied via JYX is protected by copyright and other intellectual property rights, and duplication or sale of all or part of any of the repository collections is not permitted, except that material may be duplicated by you for your research use or educational purposes in electronic or print form. You must obtain permission for any other use. Electronic or print copies may not be offered, whether for sale or otherwise to anyone who is not an authorised user. 
Health Promotion in Sport Coaching:

Coaches and Young Male Athletes'

Evaluations on the Health Promotion

Activity of Coaches

by

Sami Kokko, Jari Villberg and Lasse Kannas

Reprinted from

International Journal of

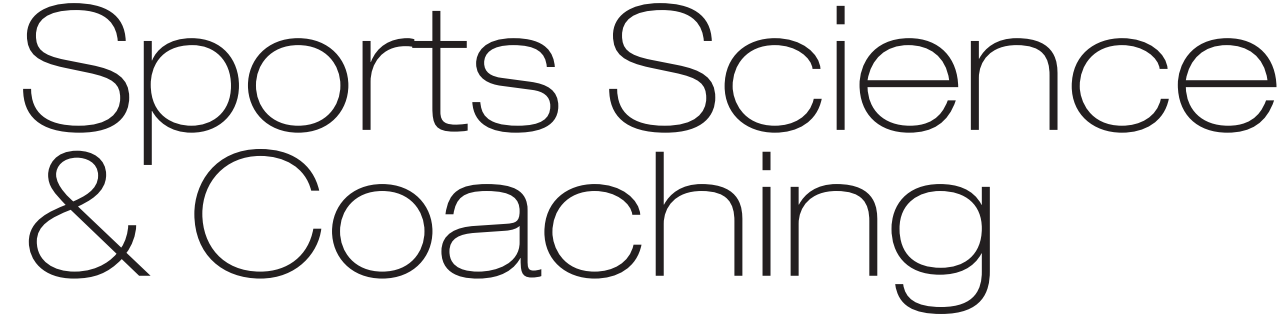

Volume 10 - Number 2+3 • 2015 


\title{
Health Promotion in Sport Coaching: Coaches and Young Male Athletes' Evaluations on the Health Promotion Activity of Coaches
}

\author{
Sami Kokko, Jari Villberg, and Lasse Kannas \\ Research Center for Health Promotion, Department of Health Sciences, \\ University of Jyväskylä, Finland \\ E-mail: sami.p.kokko@jyu.fi
}

\begin{abstract}
Sport coaches have paradoxical attitudes towards addressing health promotion as a part of their coaching practice: health is recognized as an important factor, but not greatly invested in. Overall, the extent to which youth sport coaches take health promotion into account has been unclear. Therefore, it is the intention of this study to clarify this situation. The results show that coaches evaluate their own activity on health promotion as being relatively active, whereas young male athletes' evaluations reveal a wide gap in how they perceived the coaches' activity. Young male athletes perceived their coaches as being substantially more passive in comparison to coaches' self-evaluations. This difference may indicate either that coaches' health promotion activity is generally infrequent or that what is done is broadly ineffective. Either way, as the global health-related problems of decreasing physical activity, increasing sedentary lifestyles, and obesity are all issues affecting youths attending sports clubs, arguably there is a need for youth sport coaches to invest more in health promotion activities. However, the coaches need more support from the sports clubs.
\end{abstract}

Key words: Attitudes, Health Education, Physical Activity, Sedentary Lifestyle, Youth Sport Coaches

\section{INTRODUCTION}

The main functions of the youth sports club activities are, firstly, to organise physical activities (PA) for its members (physical activity perspective) and, secondly, to optimize sports performance and athlete development (athlete development perspective). For a long time, the research findings on physical activity behaviours have been favourable to those youth participating in club activities [1,2]. However, more recently, research has indicated that even a third of these young "athletes" do not reach weekly physical activity recommendations [3]. Moreover, studies among Finnish 13-15 year-old elite athletes

Reviewers: Jim McKenna (Leeds Beckett University, UK)

Danny Mielke (Eastern Oregon University, USA) 
revealed a gap of 4.5-5.5 hours of physical activity per week $[4,5]$ when compared to the generally accepted criteria of 10,000 hours, or ten years (approx. 19 hours per week ${ }^{1}$ ), for young athletes to reach elite-level expertise [6].

Additional to the above perspectives, the majority (81\%) of Finnish sports clubs have stated that healthy lifestyles is one of the fundamental aims of their activities [7]. However, the research results show that young athletes, especially boys, together with having positive health behaviours like less frequent smoking [8], also have shortcomings in some nutritional issues [9, 10], binge-drinking [11-13] and oral tobacco (snuff) use [14, 15], when compared to their non-athlete peers. In addition, the Finnish young elite athletes slept an average of 8.5 hours \pm 58 minutes, while many athletes slept less, some considerably less, than the recommended 9 hours [5]. Also, over half of the 13 - 15 year old athletes spent more time daily in front of media than the recommended maximum of 2 hours [5]. Thus, the automatic positive contribution of sports club activities to young participants' health behaviours can be seriously undermined.

The above shortcomings, which are more prevalent to male than female athletes, are in line with the risk factors of the major health problems for males overall. Men have a propensity to risky behaviours such as smoking, alcohol drinking, drug taking and low levels of physical activity, high levels of obesity and a generally unhealthy diet [16]. These preventable risk factors are among the principle causes of premature death and morbidity in men; over half of premature male deaths are avoidable [16]. These, in turn, highlight the importance of the lifestyle factors among young athletes, not only from the athlete development perspective, but also from the public health perspective.

These shortcomings in the health behaviors of young athletes have many effects on their performance and development as athletes; if a third of sports club participating youth are not physically active enough even for their health (compared to PA recommendations), how could they become elite-level athletes? The significance and effects of health behaviors can be demonstrated by changing those un-healthy behaviors. For example, shortcomings like a lack of sleep, unbalanced diet, irregular eating patterns, abuse of substances, excessive screen time, and overuse of energy drinks, all decrease psychophysical alertness for training, disturb learning and slow recovery from training. In addition to these fairly direct effects of unhealthy behaviors, many indirect (chain) effects can be found. For example, a shortage in sleep leads to tiredness, which again leads to feelings of dizziness, restlessness, hyperactivity, and unbalanced moods, which subsequently reduces alertness for training and further decreases the optimal training effect [e.g. 17-19]. Similar chain-effects can be traced to many health topics.

When looking at how the health behaviours of the young athletes could be improved, the role of a coach becomes crucial, because coaches operate and interact with them on a dailybasis. A coach's role becomes even more influential when the informal educational nature of a sports club is recognised [20]. Research around health promotion activities in a sports club setting has so far concentrated on club policies and practices [21-24]. There is little research on coaches' health promotion activity, and even less research on this issue from the perspective of young athletes. Thus, the aim of this study was to examine the extent to which youth sports coaches have taken health promotion into account as a part of coaching practice and to compare coaches and young (14 to 16 years old) male athletes' perceptions on coaches health promotion activity. Health promotion activity was examined under three domains: 1) sports performance-related actions, 2) non-performance-related actions, and 3) health topicsrelated actions.

${ }^{1} 10.000$ hours equally divided to ten years in order to demonstrate the gap between recommendation and realization, while recognising that in reality training volume increases with age and that there is a risk of excessive exercise. 


\section{METHODS}

\section{DATA COLLECTION AND MEASUREMENT}

The data collection was carried out in two parts during 2007. This procedure ensured that data were collected at similar times during both the summer and the winter sports seasons. The sampling was club-based, meaning that the clubs from four sports disciplines (soccer, ice-hockey, track and field and cross-country skiing), were firstly discretionarily ${ }^{2}$ selected, and thereafter both coaches and young athletes from these clubs were randomly selected. For inclusion, coaches were currently coaching 14 to 16 year old youths, mainly boys; athletes were included if they were 14 to 16 years old. Overall, the data included 97 sports clubs, and coaches health promotion activity was evaluated by 240 coaches and 646 young athletes (Table 1).

The data in the present study were collected by questionnaires. Each informant group (coaches and athletes) had specific questionnaires, in which the content was largely the same, but the orientation of the questions differed: Coaches were questioned on the extent to which they had taken specific health promotion activities into account, and athletes were questioned about how they had perceived the health promotion activities delivered by the coaches. The questionnaires consisted of several health promotion-related questions, with three specific question batteries being used. These batteries describe different health promotion activity (HPA) domains, and examined the extent to which coaches had taken into account health promotion as a part of the coaching practice, with relation to the following subject matters: 1) sports performance-related factors (practices/competition); 2) non-performance-related factors (other sports club time); and 3) health-topics (Tables 2-4).

The original question format for coaches under the first battery was "To what extent have you taken into account the following matters during the sports performance, i.e; practice/competition and/or while planning it?" (Table 2). For the second battery, the original question format was "To what extent have you taken into account the following matters during non-performance time within club activities, i.e. time other than practice/competition, such as locker room or excursion activities?" (Table 3) Similarly, for the athletes, the following question formats were used: "To what extent do the following claims describe your coaches' activities during the sports performance?" (Table 2) And "To what extent do the following claims describe your coaches' activities during non-performance time within club activities, i.e. time other than practice/competition, such as locker room or excursion activities?" (Table 3$)$.

The third question battery related to what extent a coach had discussed various health topics with young athletes. The question for the coaches was: "To what extent have you discussed at least the fundamentals of the following health topics?" The question for the athletes was: "To what extent has your coach discussed the following health topics with you?" (Table 4).

The response set was a 5-point Likert scale for all the question batteries, but with slightly different formatting depending on the question format: for the coaches $1=$ not at all, $2=$ to some extent, $3=$ moderately, $4=$ much and $5=$ very much; and for the athletes $1=$ not at all, $2=$ not well, 3 =somewhat, $4=$ well and $5=$ very well. For reporting the 5 -point Likert scale, answers were reduced to a 3-point scale, and combined to the same scale by merging two mid-values $=$ some $(2=$ to some extent/not well and $3=$ moderately/somewhat $)$ and two

${ }^{2}$ Cluster sampling, with the following club-based characteristics noticed: club size, discipline, geographical location and certification by the Young Finland association. 
今ิ

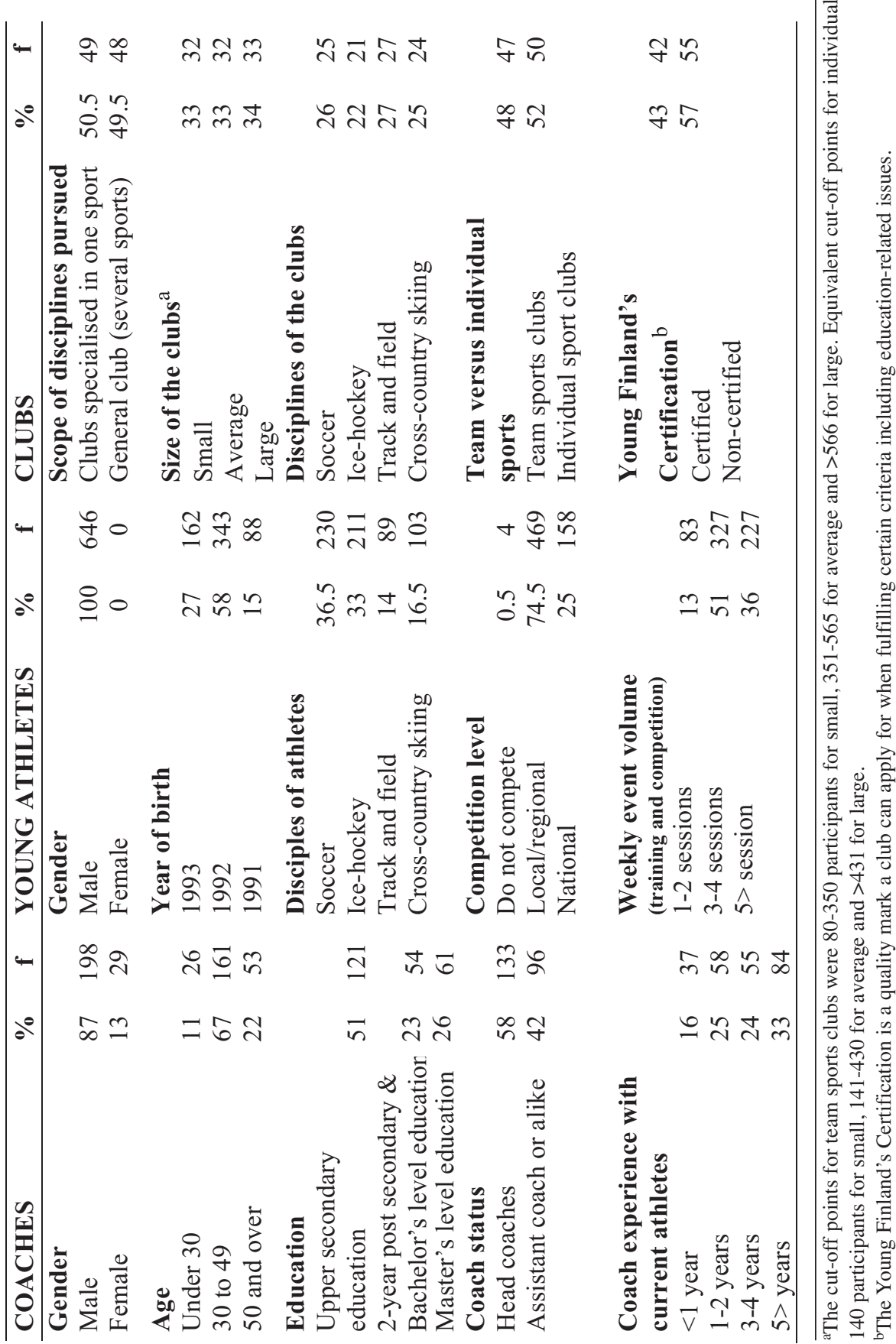


topmost-values $=$ a lot $(4=$ much/well and $5=$ very much/very well $)$. The lowest value remained the same $(1=$ not at all i.e. $1=$ no).

\section{STATISTICAL ANALYSIS}

Data analyses were started by reviewing percentage distributions and Chi-square tests. After this, a 5-point Likert scale was reduced to a 3-point scale as described above and differences between respondent groups within each question battery examined using mean values and analyses of variance. Finally, in order to compare coaches' health promotion activity between respondent groups under the three health promotion activity domains, sum variables were created for each separate respondent group. Internal consistency for each question battery was examined by factor analyses. Cronbach alpha-coefficient values for these scales ranged .68 to .94 . Differences between respondent groups were tested by logistic regression analyses. For this the scale was dichotomised by $33 \%$ splitting (value 1 for highest third and value 0 for the rest) under every question battery and for both respondent groups. All the data analyses were conducted using SPSS Version 15.0, employing a 95\% confidence level.

\section{RESULTS}

COACHES' HEALTH PROMOTION ACTIVITY CONCERNING SPORTS PERFORMANCE-RELATED MATTERS

The first question battery consisted of claims on coaches' awareness concerning sports performance-related health matters (Table 2). On average, the coaches evaluated themselves as being relatively active on every item, with the lowest mean-value being 3.43 (scale 1-5). A clear majority of coaches evaluated themselves as being very active in recognizing the youth equally (92\%) and for respecting sport regulations (92\%). More than two-thirds of coaches also claimed similar activity levels for five other themes (Table 2). Coaches reported the lowest activity under the domain on providing training at the best possible time of day, and for supporting/encouraging interactions between athletes during training/competition. The majority of youths reported that their coaches were active on safety issues (75\%), but only about half of the athletes stated that their coach had been active concerning the other claims (Table 2). Interestingly, and paradoxically, athletes reported a higher activity level from coaches on the statements where coaches had reported the lowest activity; interactions during training/competition (youth 64\%, coaches 53\%), and concerning time of the training sessions (youth $76 \%$, coaches $64 \%$ ).

There were significant differences between respondent groups under six of nine themes (Table 2). For example, young athletes reported their coaches being much less active, even passive, on recognizing the body-size and skill levels of youth in training (Coaches 3.69 vs. Youth 2.26; $\mathrm{p}<.001)$. Significant differences were discovered also on estimates of coaches' activity concerning supporting sports regulations and respecting competitors and referees, treating athletes equally, enjoyment of training, and allowing interactions during training/competition (Table 2).

In matters related to sports performance, the coaches' estimates were more positive than those of athletes (Coaches 3.51 vs. Youth $3.13 ; \mathrm{p}<.001$ ). The coaches were thirteen times more likely to estimate themselves as being active health promoters as the youths $(\mathrm{OR}=$ $13.07, \mathrm{p}<.001)$.

\section{COACHES' HEALTH PROMOTION ACTIVITY CONCERNING NON- PERFORMANCE-RELATED MATTERS}

The second question battery was directed to the coaches' awareness concerning 


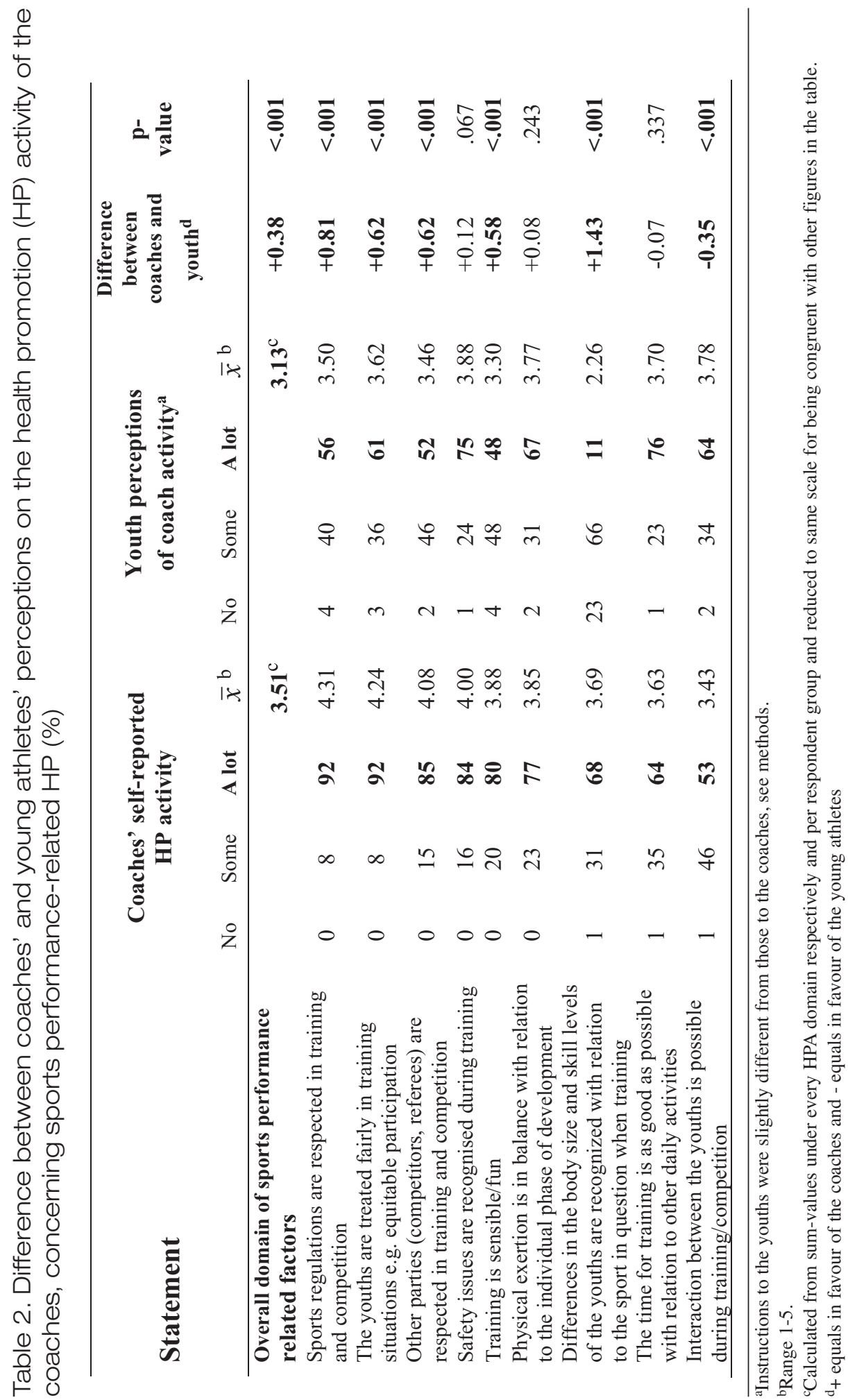




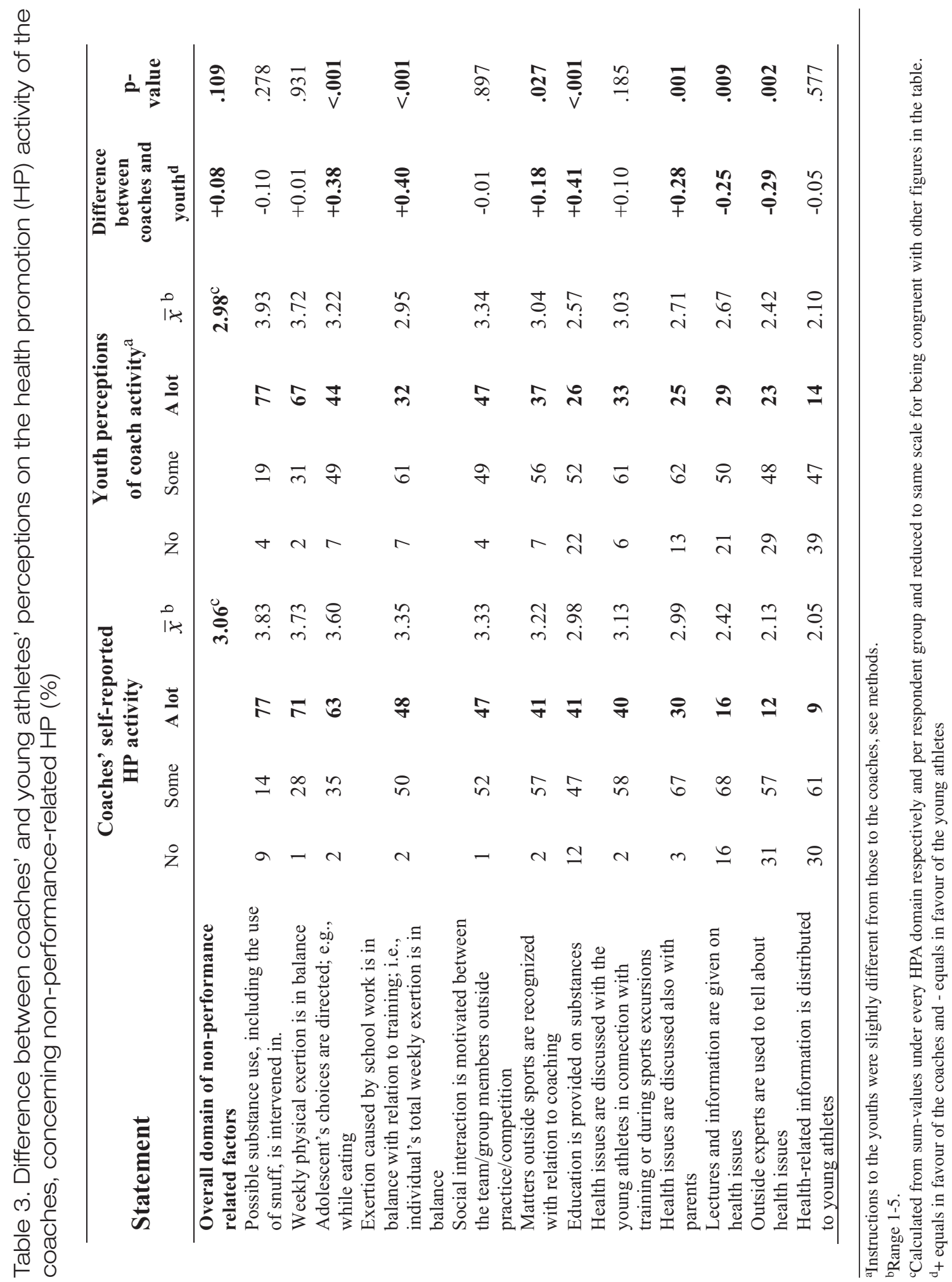


non-performance related health promotion (Table 3). Again, coaches were more positive about their activity level, although there were explicit differences between several issues when compared to the young athletes' evaluations. Coaches consistently reported actively taking into account substance use intervention if use had occurred (77\% a lot). They also reported actively advising the adolescents during daily situations, including during eating (71\% a lot) and concerning balance in weekly physical exertion (63\% a lot). Other nonperformance related health promotion was less actively recognised and coaches' evaluations varied (Table 3). Health education-related activities, such as lectures given, were seldom noted. Most youths evaluated the two top-ranked claims similarly to coaches. Thereafter, the youth evaluations were divided; about half stated their coach very actively acknowledged given issues and the other half reported moderate-level activity by the coaches.

On the whole, there was no significant difference between coaches and young athletes evaluations in this domain (Coaches 3.06 vs. Youth 2.98; p=.109). However, coaches' and athlete's evaluations were similar for five of the 12 themes (Table 3). In the seven differences, youths reported lower levels of coach activity than the coaches.

\section{COACHES' HEALTH PROMOTION ACTIVITY CONCERNING HEALTH TOPICS}

The third question battery was aimed towards various health topics. Again, the youth perceptions differed widely from those of the coaches. The majority of the coaches reported they had often discussed issues relating to risks of being physically active while ill (74\%), sleep/rest (74\%) and injury prevention (64\%) with their athletes. Almost two thirds of the coaches reported being active in promoting hygiene. Physical activity, nutrition and substance-related topics were less acknowledged, with about half reporting being active often, and the other half to some degree. Regarding the subjects of substances and violence, $10-20 \%$ of the coaches reported never to have raised these issues, and over half of the coaches said they had never discussed sexuality-related matters. The young athletes identified the same top-three topics, and their "a lot" answers matched the ranking of the coaches (Table 4).

The young athletes' evaluations were notably lower-level than those of the coaches. There were significant differences between coaches' and young athletes' evaluations under eleven claims out of thirteen (Table 4). The only "positive" agreement was regarding injury prevention (Coaches 3.57 vs. Youth 3.44; $\mathrm{p}=.141$ ). Another agreement was evident regarding sexual-issues, under which both groups stated coaches being very passive (Coaches 1.64 vs. Youth 1.59; $\mathrm{p}=.460)$. Overall, coaches were more than thirteen times more likely $(\mathrm{OR}=$ $13.37, \mathrm{p}<.001)$ than athletes to evaluate their health promotion activity under this domain as being active.

Although coaches and young athletes agreed on some claims concerning coaches' health promotion activity, and there was no difference in the non-performance domain (Table 3), the young athletes more frequently reported a lower-level of coach recognition/activity. This was also true when sports performance (Table 2) and health topics (Table 4) domains were examined as separate entities.

\section{DISCUSSION}

The results of this study positively indicate that youth sport coaches had been quite actively addressing issues such as safety promotion, suitable training time, balance in physical exertion with relation to individual development phase, and unbiased treatment of the youth. These sports performance-related actions were those best recognised by the coaches. 


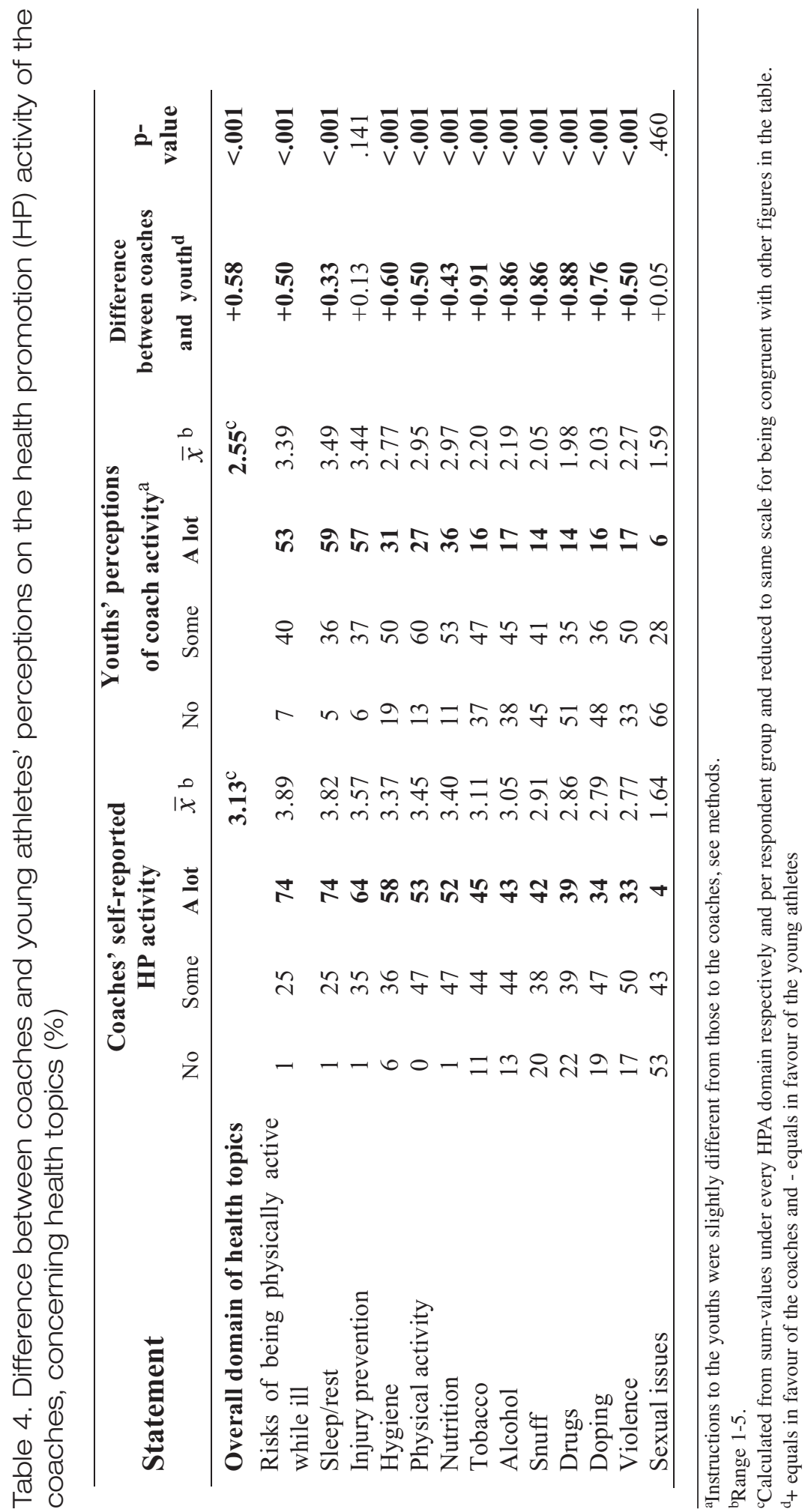


Non-performance related actions were less frequently realised, with health education rarely addressed. For health topics, factors closest related to sports performance were again relatively actively enacted, with other topics neglected. Substance-related topics were only seldom addressed, while sexuality-related topics were very seldom addressed. The latter gains more importance when issues like deviant sexual orientations or sexual abuse remain taboos in sports [25-27].

One important issue within the results was that the athletes reported that the coaches had not sufficiently acknowledged the role of differences in body size and/or skill levels in training. These factors have been highlighted as important areas to recognize for maintaining motivation [28], which, together with physical and motor development, is one of the major issues contributing to the high drop-out rates in organised sports [e.g. 29]. Dropout, in turn, has repeatedly been explained through self-determination theory and negative results in its factors, like amotivation, external regulation, and/or low level of autonomy [30]. Coaches, especially in team sports, should recognise the differences in body size and skill levels and tailor training accordingly.

The results of this study confirm previous research findings indicating that coaches have not yet converted comprehensive understanding of athlete development into the daily practices. There are several possible reasons for this. One of the most prevalent features in sports systems that are based on the voluntary civil activity of the coaches - as prevails in Finland - is the coaches lack of time, know-how and competency on features beyond sportspecific skills. The vast majority of ice-hockey coaches in Finland stated that while they see health promotion as an important issue and would invest in it more than they currently did, they didn't know what to do or how to implement it [31]. This was also seen in the current study, especially under the health issues that need either specific knowledge or a sensitive stance from the coach; themes like substance use or sexuality. Coaxial findings have been found under coaches' doping-related knowledge and preventive actions [32]. Coaches' passivity on health promotion might also relate to what is debated between coaching science and its educational relationship - coaching is a complex socio-pedagogical process [33], in which the amateur coaches most likely experience a lack of educational competence. These beyond-sport-demands, at the same time, might increase the expectations for amateur coaches so much that the recruitment of voluntary coaches becomes even more difficult. The reality between expectations and possibilities need to be balanced.

One further possible reason contributing to this passivity regarding health issues is that the links to sport performance are not recognized, understood or even promoted among coaches. In the current study, even issues raised in this paper that represent major health threats - including lack of physical activity, increased sedentariness, and nutritional drawbacks - were less recognised by the coaches. The shortcomings in these behaviors among young athletic males not only impair athlete development, but also contribute to worsened public health.

What then needs to be done and by whom? First of all, it has been recommended that it is important to review the coaching context when designing coach development initiatives [34]. The results of this study are in line with earlier reported health promotion guidance activity of youth sports clubs, where the clubs had similarly guided their coaches most actively concerning sports-performance related actions and much less on other features [22]. Thus, the development needs to be started at club level [23, 24, 35, 36]. Sports clubs should not only highlight the health-related issues as important in their operational principles, but also offer guidance and education for the coaches in these issues. Clear models in nutrition education for youth, for example, do exist. Coach education, in turn, is an important vehicle 
to get the health issues on the coaching agenda. In Finland, the current coach and instructor education development process for level 1 to 3 coach education includes health promotion as one of three main elements, alongside pedagogical and physiological entities [37].

Concerning coach activity, the interactions with athletes could be improved. It has, for example, been found that sports coaches rarely have in-depth discussions with their athletes, whereas young athletes would like more frequent discussions with the coaches about both sports-related and non-sports-related issues [5]. This is especially important as the young athletes perceive coaches as being more than just a coach; i.e. many coaches are seen in as parental figures [38]. More discussion does not require new or complex methods, but can be easily realised through more frequent interactions between coaches and athletes. Parents may also be called upon to complete the athletic triangle i.e. the coach-parent-athlete triad [39]. The latter is especially important with relation to health issues.

The validity of the study was ensured in a number of ways. Both coaches and young athletes were included as respondents. This triangulated the coaches' self-evaluations. The themes within the questions regarding coaches' health promotion activity were compiled to include dimensions of most youth sport club activities, not just those closest to sport performance. The themes under the first two question batteries were derived from core health promotion actions which are universally declared, like the Ottawa Charter action areas [40]. The themes also encompassed all three dimensions of health, namely physical, mental and social. The third question battery focused on core topics affecting health behaviour.

The reliability of study was assured by collecting the data and sampling at the latter half of the season. This gave all respondents the best possible conditions to retrospectively review the ongoing season. On the other hand, one can question whether both the youth and coaches remembered all the activities done during the past season. The sampling procedure of both clubs and respondents was detailed and carefully executed. As some distributions were skewed, data were analysed using both parametric and non-parametric testing. In addition, scale reliability was assured by investigating the internal consistency of the variables under each question battery by factor analyses. The Cronbach's alpha-coefficient values confirmed the reliability with values between .68 and .94 .

The study continues to have some limitations. First, it is based on self-reported data, which may be subject to social desirability bias. For example, the coaches, when evaluating their own activities, might feel social pressure to acknowledge these matters, and therefore overestimate their activity. The appropriate amount of health education by a coach in order to evoke positive answers from young athletes could also be questioned. At the same time, it is not clear how the existing health promotion activity influenced athlete behaviour. Second, all the responding youth were boys. Girls tend to be more interested in health issues in general, as they have been discovered to have better health literacy [41]. Third, sport disciplines were not addressed separately. The nature of each sports discipline is specific, for example, in individual sports the training sessions are socially different than in team sports, where other peers are always involved. Also, a coach-athlete-relationship forms differently. Fourth and finally, although the data was collected in 2007, there have not been any major changes in the way the sports clubs and coaching are organized in Finland. Thus, we believe the data is still relevant, valid and representative.

In future research, genders should be equally involved and/or girls sports and coaching studied similarly to the boys. The health promotion activity of the coaches should be explored sports discipline specifically, at least between individual and team sports. As for coaches, gender differences among coaches should be studied. After this descriptive overview, there is a need to outreach the data by using more authentic methods, like 
observation and videotaping. Also, an action research-type participatory approach would give more authentic information on the health promotion activity of youth sports coaches. The latter becomes a high priority due to the vast gap between coaches and young athletes' evaluations as described in this paper. Finally, a link between the health promotion activity of the youth sports clubs and coaches' activities could be taken into closer examination.

\section{CONCLUSION}

The major health-related concerns of modern societies, namely a lack in overall physical activity, and an increase in sedentariness and obesity, are already concerns of young athletes and, at worst, may impair athlete development. In addition, there still seems to be a gap between sport coaches' aim on comprehensive athlete development and actual coaching behaviours. In this study coaches claimed to be most active concerning sports performancerelated action and least active regarding health promotion in areas away from athletic performance. One of the most prevalent reasons behind this passivity is the amateur nature of youth sports coaching with a corresponding lack of time and know-how. Coaches should be supported in health issues by coach education and club-level activities.

\section{REFERENCES}

1. Sallis, J.F., Prochaska, J.J. and Taylor, W.C., A Review of Correlates of Physical Activity of Children and Adolescents, Medicine \& Science in Sports \& Exercise, 2000, 32(5), 963-975.

2. Vuori, M., Kannas, L. and Tynjälä, J., Nuorten Liikuntaharrastuneisuuden Muutoksia 1986-2002 [The Changes in Youth Physical Activity During the Years 1986-2002], in Kannas, L., ed., Koululaisten Terveys ja Terveyskäyttäytyminen Muutoksessa, WHO-Koululaistutkimus 20 Vuotta, [The Health and Health Behaviours of School-Aged Children in Change. Twenty Years of HBSC-Study], Jyväskylän Yliopisto (University of Jyväskylä), The Publications of the Research Center for Health Promotion 2, 2004, 113-139.

3. Eiosdottir, S.P., Kristjansson, A.L., Sigfusdottir, I.D. and Allegrante, J.P., Trends in Physical Activity and Participation in Sports Clubs among Icelandic Adolescents, European Journal of Public Health, 2008, 18(3), 289-293.

4. Hakkarainen, H., Härkönen, A., Niemi-Nikkola, K., Mäenpää, P., Potinkara, P., Kujala, A., Jaakkola, T. and Kantosalo, K., eds. Selvitysraportti - Urheilevien Lasten ja Nuorten Fyysis-Motorinen Harjoittelu [Report on Physiological and Motor Training of Sporting Children and Adolescents], Nuori Suomi ry, Suomen Olympiakomitea ry, Suomen Valmentajat ry., SLU-Paino, Helsinki, 2008.

5. Kokko, S., Villberg, J. and Kannas, L., Nuori urheilijan polulla. 13-15-Vuotiaiden Urheilijoiden Arvioita Harjoitusmääristään, Harjoittelun Monipuolisuudesta Sekä Elämäntavoista. [Youth on an Athlete Pathway. The Evaluations of 13-15 Year Old Athletes on Their Training Volume and Diversity and Lifestyles.]. Publications of Research Center for Health promotion at University of Jyväskylä and The Young Finland Association, 2011a, ISBN: 9789525846270 (PDF).

6. Backer, J., Early Specialization in Youth Sport: a Requirement for Adult Expertise?, High Ability Studies, 2003, 14(1), 85-94.

7. Koski, P., Liikunta- ja Urheiluseurat Muntoksessa [Sports Clubs in Change], SLU-Julkaisusarja 7. SLUPaino, Helsinki, 2009.

8. Melnick, M.J., Miller, K.E., Sabo, D.F., Farrell, M.P. and Barnes, G.M., Tobacco Use among High School Athletes and Nonathletes: Results of the 1997 Youth Risk Behavior Survey, Adolescence, 2001, 36(144), 727-747.

9. Aerenhouts D., Hebbelinck M., Poortmans J. and Clarys P., Nutritional Habits of Flemish Adolescent Sprint Athletes, International Journal of Sport Nutrition and Exercise Metabolism, 2008, 18(5), 509-523.

10. Cavadini C., Decarli J.G., Narring F.M. and Michaud P.A., Food Habits and Sport Activity During Adolescence: Differences Between Athletic and Non-Athletic Teenagers in Switzerland, European Journal of Clinical Nutrition, 2000, 54(1), S16-S20. 
11. Ford, J., Alcohol Use among College Students: A Comparison of Athletes and Nonathletes, Substance Use and Misuse, 2007, 42(9), 1367-1377

12. Kannas, L., Vuori, M., Seppälä, H.-R., Tynjälä, J., Villberg, J., Välimaa, R. and Ojala, K., Suojaako Urheiluseuratoiminta Nuoria Päihteiltä ja Tupakalta [Do the Sports Club's Actitivities Protect from Intoxicants and Tobacco], Liikunta \& Tiede, 2002, 39(4), 4-11.

13. Peretti-Watel, P., Guagliardo, V., Verger, P., Pruvost, J., Mignon, P. and Obadia, Y., Sporting Activity and Drug Use: Alcohol, Cigarette and Cannabis Use among Elite Student Athletes, Addiction, 2003, 98, 1249-1256.

14. Haukkala, A., Vartiainen, E. and de Vries, H., Progression of Oral Snuff Use among Finnish 13-16-Yearold Students and Its Relation to Smoking Behavior, Addiction, 2006, 101(4), 581-589.

15. Rolandsson, M. and Hugoson, A., Factors Associated with Snuffing Habits among Ice-Hockey-Playing Boys, Swedish Dental Journal, 2001, 25(4), 145-154.

16. European Commission, The State of Men's Health in Europe, Luxembourg, The European Commission, 2011 .

17. Samuels, C., Sleep, Recovery, and Performance: The New Frontier in High-Performance Athletics, Neurologic Clinics, 2008, 26(2008), 169-180.

18. Sargenti, C., Halson, S. and Roach, G.D., Sleep or Swim? Early-Morning Training Severely Restricts the Amount of Sleep Obtained by Elite Swimmers, European Journal of Sport Science, 2014, 14(1), 310-315.

19. Alhola, P. and Polo-Kantola, P., Sleep Deprivation: Impact on Cognitive Performance, Neuropsychiatric Disease and Treatment, 2007, 3 (5), 553-567.

20. Kokko S., Green L.W. \& Kannas L. A review of settings-based health promotion with applications to sports clubs. Health Promotion International. 2014; 29, 494-509.

21. Kokko, S., Kannas, L. and Villberg, J., Health Promotion Profile of Youth Sports Clubs: Club Officials' and Coaches' Perceptions, Health Promotion International, 2009, 24(1), 26-35.

22. Kokko, S., Kannas, L., Villberg, J. and Ormshaw, M., Health Promotion Guidance Activity of Youth Sports Clubs, Health Education, 2011b, 111(6), 452-463.

23. Casey, M., Payne, W.R. and Eime, R.M., Organisational Readiness and Capacity Building Strategies of Sporting Organisations to Promote Health, Sport Management Review, 2012, 15(1), 109-124.

24. Geidne, S., Quennerstedt, M. and Eriksson, C., The Youth Sports Club as a Health-Promoting Setting: An Integrative Review of Research, Published online 24 January 2013 Scandinavian Journal of Public Health DOI: $10.1177 / 1403494812473204$

25. Garcia, C., Gender Expression and Homophobia: A Motor Development and Learning Perspective, Journal of Physical Education, Recreation, and Dance, 2011, 82(8), 47-49.

26. Kokkonen, M., Seksuaali- ja Sukupuolivähemmistöjen Syrjintä Liikunnan ja Urheilun Parissa, [The Discrimination of Sexual- and Gender Minorities in Sports], Publications of National Sports Council 5, 2012, 54 pages, ISBN: 978-952-263-143-5 (PDF).

27. Le Blanc, R. G., and Jackson, S. J., Sexuality as Cultural Diversity within Sport Organizations, International Journal of Sport Management and Marketing, 2010, 2(1/2), 119-133.

28. Seghers, J., de Martelaer, K. and Cardonc, G., Young People's Health as a Challenge for Physical Education in Schools in the Twenty-First Century: The Case of Flanders (Belgium), Physical Education and Sport Pedagogy, 2009, 14(4), 407-420.

29. Fraser-Thomas, J., Côté, J. and Deakin, J., Understanding Dropout and Prolonged Engagement in Adolescent Competitive Sport, Psychology of Sport and Exercise, 2008, 9(5), 645-662.

30. Calvo, T.G., Cervelló, E., Jiménez, R., Iglesias, D., and Moreno Murcia, J.A., Using Self-Determination Theory to Explain Sport Persistence and Dropout in Adolescent Athletes, The Spanish Journal of Psychology, 2010, 13(2), 677-684.

31. Kokko, S. and Kannas, L., Terveyskasvatus Nuorten Jääkiekkovalmennuksessa [Health Education in IceHockey Coaching of Adolescents], Liikunta \& Tiede, 2004, 41, 45-48.

32. Backhouse, S.H. and McKenna, J., Reviewing Coaches' Knowledge, Attitudes and Beliefs Regarding 
Doping in Sport. International Journal of Sports Science \& Coaching, 2012, 7(1), 167-175.

33. Jones, R., Coaching Redefined: An Everyday Pedagogical Endeavor, Sport, Education and Society, 2007, 12 (2), 159-173.

34. Gilbert, W., Côté, J. and Mallett, C., Developmental Paths and Activities of Successful Sport Coaches. International Journal of Sports Science and Coaching, 2006, 1(1), 69-76.

35. Dobbinson, S.J., Hayman, J.A. and Livingston, P.M., Prevalence of Health Promotion Policies in Sports Clubs in Victoria, Australia, Health Promotion International, 2006, 21(2), 121-129.

36. Kokko, S., Kannas, L. and Villberg, J., The Health Promoting Sports Club in Finland - a Challenge for the Settings-Based Approach, Health Promotion International, 2006, 21(3), 219-229.

37. The Finnish Sports Association, Valmentaja - ja Ohjaajakoulutuksen Perusteet (The Principles in Coach and Instructor Education), Publication of The Finnish Sports Association, The Young Finland Association, The Finnish Sport for All Association and The National Olympic Committee, Helsinki, 2010.

38. Becker A.J., It's Not What They Do, It's How They Do It: Athlete Experiences of Great Coaching, International Journal of Sports Science and Coaching, 2009, 4(1), 93-119.

39. Smoll, F.L., Cumming, S.P., and Smith, R.E., Enhancing Coach-Parent Relationships in Youth Sports: Increasing Harmony and Minimizing Hassle, International Journal of Sports Science \& Coaching, 2011, 6(1), 13-26.

40. WHO (World Health Organization), Ottawa Charter for Health Promotion, Copenhagen, WHO European Regional Office, 1986.

41. Koski, P., Sport: Road to Health?, in Hoikkala, T., Hakkarainen, P. and Laine, S., eds., Beyond Health Literacy. Youth Cultures, Prevention and Policy, Finnish Youth Research Network / Finnish Youth Research Society Publications 52, 2005, 295-323. 